\title{
Preservation of murals on salt loaded masonry vaults by electromigration
}

\author{
I. Rörig-Dalgaard \& L. M. Ottosen \\ Department of Civil Engineering, \\ Technical University of Denmark, Denmark
}

\begin{abstract}
Salt induced deterioration of murals in churches has increased within the last decades in Denmark. However, no lasting preservation method has been found. Either murals are repainted by conservators or placed in climate chambers which give the deterioration a break. Ion migration in a solution in an applied electric DC field is termed electromigration and is a well known and accepted transport process. In wet porous clay brick masonry, which most Danish church vaults consist of electro migration is expected to be an efficient transport mechanism for ion extraction out of the vaults. This idea was tested in the present work.

Electromigration experiments in bricks with low $\mathrm{NaCl}$ concentration (spiked into the brick by soaking) showed that it is possible to clean a brick to its initial ion content new from the factory. An experimental setup which is applicable under real conditions and with ion contents corresponding to heavily polluted church vaults (1.4 weight $\%$ chloride) showed significantly decreasing ion contents as a function of time. Experiments are ongoing to reach a harmless ion content which is thought to be a matter of duration and optimization of experimental conditions.

Simultaneously with the electromigration process varying extends of acid and base is produced due to electrode reactions. Clarifying experiments showed extreme $\mathrm{pH}$ changes and pointed out the need for developments of electrode setups to avoid these changes. New experiments with the developed electrode units reduced the $\mathrm{pH}$ changes remarkably, which make the method usable in connection with cultural heritage.

On the basis of successful laboratory results electrokinetics for extraction of ions from masonry vaults might be the missing lasting method to extract the damaging salts and thereby preserve the murals.
\end{abstract}

Keywords: electromigration, chloride extraction, $p H$ stability, church vault. 


\section{Introduction}

\subsection{The historical origin of the murals and their foundation}

The murals were used to introduce the new Christian religion in Denmark by passing on Christian stories in picture language as the majority part of the Danes were not able to read. As the early Danish art was highly affected by Christianity the murals are a valuable part of Danish cultural heritage (Nørregård-Nielsen [1]) and should therefore be preserved for many years to come.

Within the last decades increased disruption of the murals has been noticed by conservators from the Danish National Museum most probably due to changing user conditions (Larsen [2]). The reason for the deterioration is the presence of salts, especially represented by sodium chloride $(\mathrm{NaCl})$ in the vaults (Larsen [2]). As the reason for the damaging effects of the salts, different theories have been suggested. The most accepted theory considers the change from solute ions to precipitated salt crystals and the thereby connected high pressure as the reason for the disruption of the surface (Lubelli [3]). In the case of murals on the surfaces these will be deteriorated. As the salts are the reason for the deterioration of the murals, these should be extracted to ensure the murals for many years to come.

As murals are a part of Danish cultural heritage, special precautions have to be taken and as actions cannot be undone, adverse effects are even more critical than effects.

Only a few investigations have previously been made with electro kinetic salt extraction methods for the removal of salts from masonry constructions. One investigation (Demberger [4]) points out that the adverse effects are not controlled as discoloration close to the electrodes occur and $\mathrm{pH}$ values of 1 near the anode and $\mathrm{pH}$ values of 12 near the cathode was observed and measured. Another investigation (Auras and Melisa [5]) measured $\mathrm{pH} 3$ close to the anode and $\mathrm{pH} 10$ close to the cathode. Such extreme $\mathrm{pH}$ changes alter the original material significantly and cannot be accepted.

In the electro chemistry field, adverse effects due to electrode reactions are well known. In connection with remediation of soil, fly ash and wood, anion and cation exchange membranes have been used to separate the material to be remediated and the electrodes, to avoid entering the $\mathrm{pH}$ changes into the material and thereby also to optimize the remediation process (Ottosen et al [6]). Due to the special geometry of church vaults and the need to reduce maintenance new electrode units were developed especially for the use of salt extraction from church vaults. However the setup should also be applicable in the general case for removal of salts from e.g. residential blocks.

\section{Electrokinetics}

\subsection{Ion extraction}

A porous wet material can to some extent be considered as a solution regarding the pores (the exception is in the vicinity of the pore walls where electric double 
layers are formed). By applying an electric DC field the ions start to move. Negative ions (anions) will be transported towards the positive pole (anode) and visa versa. In the case of church vaults sodium chloride ions are the dominating ions (Larsen [2]) and in an applied electric field chloride ions will be transported towards the anode and the sodium ions will be transported towards the cathode (Acar [8]), see Figure 1.

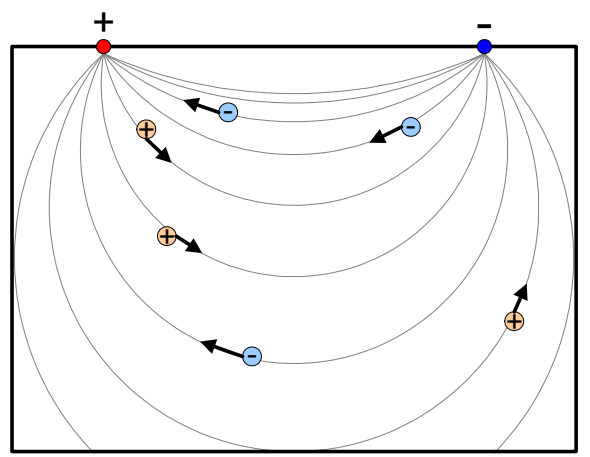

Figure 1: Principal sketch of potential and current distribution in a vertical plane along the line of electrodes with ion migration, (van Nostrand [7]).

By placing a removable layer (e.g. clay) between the brick and the electrodes the transported ions can eventually be removed.

\section{2 pH stability}

When an electric DC field is applied to a wet porous material the current will be carried by the ions in the liquid and electrons in the electrodes. The transformation processes between the electrons in the electrodes and the ions in the liquid are termed electrode processes (1) and (2) and they result in a varying extent of acid and base formation.

$$
\begin{array}{ll}
\text { Cathode (-) process: } & 2 \mathrm{H}_{2} \mathrm{O}+2 \mathrm{e}^{-} \rightarrow 2 \mathbf{O H}^{-}+\mathrm{H}_{2}(\mathrm{~g}) \\
\text { Anode }(+) \text { process: } & \mathrm{H}_{2} \mathrm{O} \rightarrow 2 \mathbf{H}^{+}+1 / 2 \mathrm{O}_{2}(\mathrm{~g})+2 \mathrm{e}^{-}
\end{array}
$$

Dependent on the electrode material and ions in the vicinity of the anode, several additional processes may occur like decomposition of the electrode material.

When working with cultural heritage it is of outstanding importance to ensure maintenance of the original material. In a previous investigation (Ottosen [9]) it was found that the produced acidification at the anode can be neutralized by placing a clay rich in carbonates between brick and the metallic anode though developments are needed to neutralize the produced base by the cathode.

In the present work another material/component was searched for in addition to the clay to neutralize the produced $\mathrm{OH}^{-}$. As this additional material/component at the present time is the object of possible patenting it will not be further described in this paper. However, the results will be presented. 


\section{Experimental}

\subsection{Bricks for the investigation}

The bricks used in the experiments are made for renovation purposes of older buildings (handcrafted, burned in a circular kiln) by Falkenløwe, Denmark. Comparison of investigations has shown similar properties between original Danish medieval bricks and Falkenløwe bricks (Larsen [10]). The degree of capillary saturation, $S_{\text {cap }}$, was $14.0+/-0.5$ weight $\%$ (found by submerging the bricks into a solution for 3 days). The dimensions were approximately $28 \mathrm{~cm} \times 7 \mathrm{~cm} \times 14 \mathrm{~cm}$ were the $14 \mathrm{~cm}$ thickness corresponds to the thickness of an average church vault. The dry mass of the bricks are $5032+/-63 \mathrm{~g}$. The $\mathrm{pH}$ was measured to be $8.6+/-0.1$.

\subsection{Sampling description}

The presence of damaging salts is mainly a problem that comes into existence as times goes by. To make a diagnosis of e.g. an existing building in Denmark, $10 \mathrm{~mm}$ drilling samples are made. As this method is thought to be tested on existing buildings and to make laboratory experiments as comparable as possible with real conditions, the same sampling method is used in the present laboratory work. The size of $10 \mathrm{~mm}$ is a compromise to obtain both representative results on both water and ion contents and to still minimize the size of the drilling hole. Drilling samples on existing church vaults are made with a $6 \mathrm{~mm}$ drill to minimize the holes (Larsen [2]).

To map chloride movements within the electric field, 9 drilling samples were made from each brick by dividing the brick into 3 equal pieces both vertically and horizontally. The chosen distances from the electrodes take the current distribution into account and are shown in Figure 2.

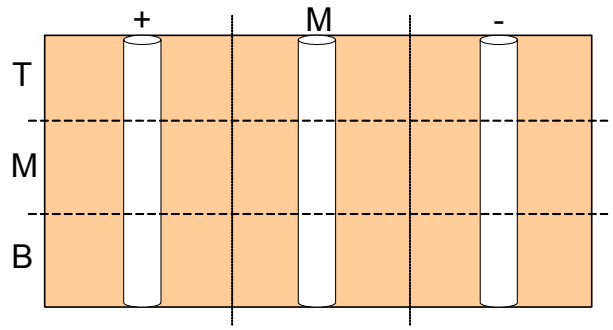

Figure 2: Principal drawing of the sampling. Each brick is divided into 3 pieces both horizontal and vertical. The upper third closest to the electrodes is called top piece and the brick pieces just below the positive electrode is called + e.g. upper left piece is called $+T$.

\subsection{Analytical}

$\mathrm{Cl}^{-}$and $\mathrm{Na}^{+}$, which were the ions added to the bricks, are water soluble and simple extractions in distilled water were made to evaluate concentrations. For 
the chemical analysis the brick material was drilled out with a $10 \mathrm{~mm}$ drill. The extractions were made with around $5 \mathrm{~g}$ dry brick powder and $25 \mathrm{ml}$ distilled water. The suspension was placed on a shaking table for 24 hours and $\mathrm{pH}$ was measured with a $\mathrm{pH}$ meter. Afterwards $2 \mathrm{ml}$ of the suspension was added to a mixture of $35 \mathrm{ml}$ distilled water and $1 \mathrm{ml} 1 \mathrm{M} \mathrm{HNO}_{3}$ and the chloride content was measured by a titrator (Metrohm 716 DMS Titrino). A standard solution made for control of the AAS apparatus was used to control the measured chloride content both on the AAS and on the titrator. The result showed good agreement between the standard value, AAS and titrator measurements.

\section{Laboratory experiments}

To obtain the right chloride content (i.e. comparable to what is known to be problematic in real constructions) the bricks were submerged in $\mathrm{NaCl}$ solutions. The added $\mathrm{NaCl}$ mass was calculated from the mass and total porosity of the brick. To reach the right ion content in the brick the mass of the added salt had to be taken into account as a considerable amount of salt was added. After submerging the bricks in the solution for 3 days, they were carefully wrapped in plastic to reduce evaporation.

Experiments were carried out with a design which is thought to be applicable on church vaults. As salt loaded masonry vaults with murals are very fragile due to partial deterioration, ion extraction is solely thought to be possible from the top side of the vaults and the electrodes could then be placed in bands, see Figure 3 left. To obtain a similar situation in the laboratory setup both anode and cathode were placed on top of the brick in each end, see Figure 3 right. To ensure a good contact, to ensure stable $\mathrm{pH}$ and for the accumulation of the ions a clay mixture was placed in between the brick and the electrodes.
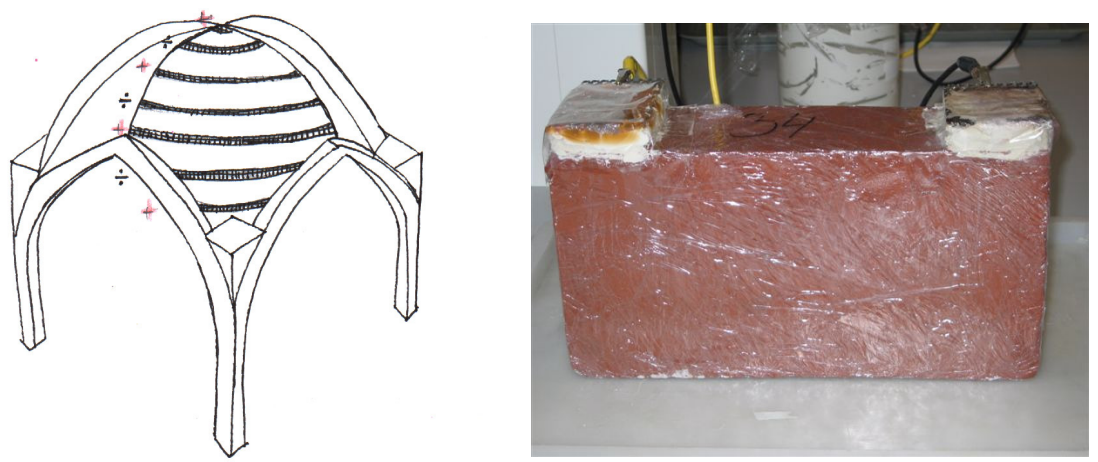

Figure 3: The left figure illustrates the electrode setup (only placed on top of the vault) and the right picture shows the laboratory setup where the electrodes also are placed only on the top. 


\subsection{Ion migration}

To evaluate the method utility even at high ion concentrations a series of experiments were carried out with a chloride content of 1.4 weight $\%$ (similar to the concentration measured in a typical Dutch church located near the coast subjected to sea-salt spray (Lubelli [3]). Experiments with an applied DC current of $40 \mathrm{~mA}$ for $0,1,3$ and 4 weeks were made to illustrate the electromigration in a brick as a function of time. See Table 1 for the experimental overview.

Table 1: Experimental overview for electromigration.

\begin{tabular}{|l|c|c|c|}
\hline Experiment & $\begin{array}{c}\text { Chloride concentration } \\
\text { (weight \%) }\end{array}$ & Current (mA) & $\begin{array}{c}\text { Duration } \\
\text { (weeks) }\end{array}$ \\
\hline EM-0 & 1,4 & 0 & 0 \\
\hline EM-1 & 1,4 & 40 & 1 \\
\hline EM-2 & 1,4 & 40 & 3 \\
\hline EM-3 & 1,4 & 40 & 4 \\
\hline
\end{tabular}

As a chloride concentration of 1.4 weight \% is very high in Danish examples, new and similar experiments with a more common chloride content (1.0 weight $\%$ ) are ongoing. This lower chloride content corresponds to a heavily polluted brick in a Danish church vault (Larsen [2]).

\section{$4.2 \mathrm{pH}$ stability}

According to the case studies and to the theory, $\mathrm{pH}$ changes will occur at the electrodes due to the applied current. To clarify the extend of $\mathrm{pH}$ changes, an experiment with a moderate current, $10 \mathrm{~mA}$ and a duration of 5 weeks was carried out with electrode units only consisting of clay and distilled water. This moderate current strength with 5 weeks duration is not enough to clean a heavily polluted brick, but it gives some identification of the extend of the $\mathrm{pH}$ changes.

Clay mixtures (not specified here due to possible patenting) were made which according to the calculations should be able to neutralize the acid and base formation for 2 weeks. A series of experiments was carried out to verify the calculated neutralizing duration times. These experiments were for comparison reasons also carried out with a current strength of 10 am with a duration of between 1-3 weeks, see Table 2 .

Table 2: $\quad$ Experimental overview for possible $\mathrm{pH}$ stability.

\begin{tabular}{|l|c|c|c|}
\hline Experiment & $\begin{array}{c}\text { Chloride concentration } \\
\text { (weight \%) }\end{array}$ & Current (mA) & $\begin{array}{c}\text { Duration } \\
\text { (weeks) }\end{array}$ \\
\hline $\mathrm{pH}-1$ & 0,5 & 10 & 1 \\
\hline $\mathrm{pH}-2$ & 0,5 & 10 & 2 \\
\hline $\mathrm{pH}-3$ & 0,5 & 10 & 3 \\
\hline
\end{tabular}




\section{Results}

The results from the ion extraction experiments with $40 \mathrm{~mA}$ for $0-4$ weeks are shown in Figure 4. According to the theory of "electric field lines" the transport of ions will at first primarily be from the top area of the brick, since the distance between the electrodes are the shortest. The removal of ions from this area will eventually result in an increased resistance and subsequently the electric field will expand further down, resulting in removal of ions even further from the top (surface). Therefore the electromigration should occur as a function of distance from the electrodes. Each point in Figure 4 illustrates the average of three horizontal drilling samples and thereby represents each point $5 \mathrm{~cm}$ and $1 / 3$ of the bricks.

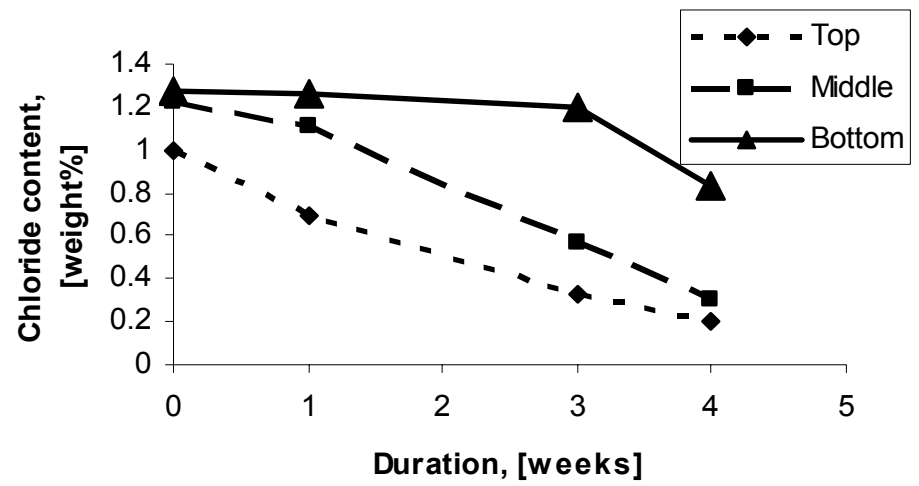

Figure 4: Development in the chloride content as a function of distance to the electrodes and time.

Figure 4 shows the actual chloride content in the brick after $0,1,3$ and 4 weeks. The change (slope on the lines) from week to week corresponds to the chloride reduction. As expected the highest slope is within the first week in the top section though with a decreasing tendency after 1 week. For the middle part minor changes occur within the first 1 week though significant reduction happens between 1 and 4 weeks. The chloride content in the bottom part does not change significantly within the first 3 weeks though between 3 and 4 weeks chloride reduction starts in this part, too. After 4 weeks duration $20.1 \mathrm{~g}$ chloride was extracted and measured in the anode clay this corresponds to a reduction of $35 \%$ in the original calculated chloride content. According to the average of the 9 measured samples a reduction of $36 \mathrm{~g}$ chloride should have occurred within these 4 weeks. The average chloride content was reduced from 1.16 weight $\%$ to 1.02 weight $\%$ ( 1 week) to 0.70 weight $\%$ (3 weeks) to 0.44 weight $\%$ ( 4 weeks). The difference in extracted chloride by the electrodes and the measured reduction in the bricks could be caused by the fact that even though the brick is wrapped in plastic evaporation will probably occur to some extend. By evaporation water and ions will be transported towards the surfaces resulting in a 
higher ion concentration just underneath the surface. This could be tested by total destruction of a brick after ending the experiment (ongoing). Illustrated by the degree of slope the current distribution is made visible and it corresponds satisfactorily with the theory as the biggest changes happen closest to the electrodes in the beginning moving further and further away from the electrodes as a function of time.

According to the theory $\mathrm{pH}$ changes occur simultaneously with the electromigration. An experiment was carried out to illustrate the extent of $\mathrm{pH}$ changes in a brick when no precautions are made to avoid $\mathrm{pH}$ changes. The experiment was applied a current of $10 \mathrm{~mA}$ for 5 weeks. See Figure 5.

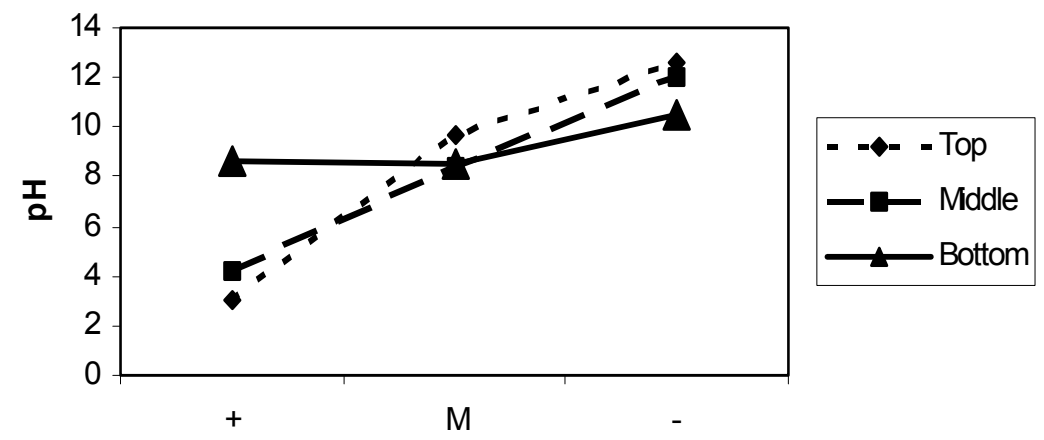

Part from the anode

Figure 5: Extent of $\mathrm{pH}$ changes in an experiment where no precautions were taken to avoid $\mathrm{pH}$ changes.

Extreme $\mathrm{pH}$ changes were measured in piece $+\mathrm{T}(\mathrm{pH}=3.1)$ and $-\mathrm{T}(\mathrm{pH}=$ 12.6). A minor deviation from the original $\mathrm{pH}$ can be accepted as it is assumed not to affect the material significantly, though extreme $\mathrm{pH}$ changes must be avoided as it e.g. influences the material strength and deterioration (Krenkler [11]). According to Figure 5 significant $\mathrm{pH}$ changes had occurred in the upper 10 $\mathrm{cm}$ (top and middle part). Meanwhile by applying moderate $10 \mathrm{~mA}$ for 5 weeks only minor chloride reduction can be expected (2.6 g chloride was accumulated by the anode unit corresponding to 0.05 weight $\%$ chloride) and as the acid and base production occurs as a function of time and applied current even more extreme $\mathrm{pH}$ changes must be expected by cleaning a heavily polluted construction if no precautions are taken.

This experiment clearly illustrates the need for $\mathrm{pH}$ control should this method be used for ion extraction from cultural heritage.

Experiment $\mathrm{pH}-1$ to $\mathrm{pH}-3$ was carried out to verify the calculated neutralizing time of 2 weeks by the applied $10 \mathrm{~mA}$, see Figure 6 . 

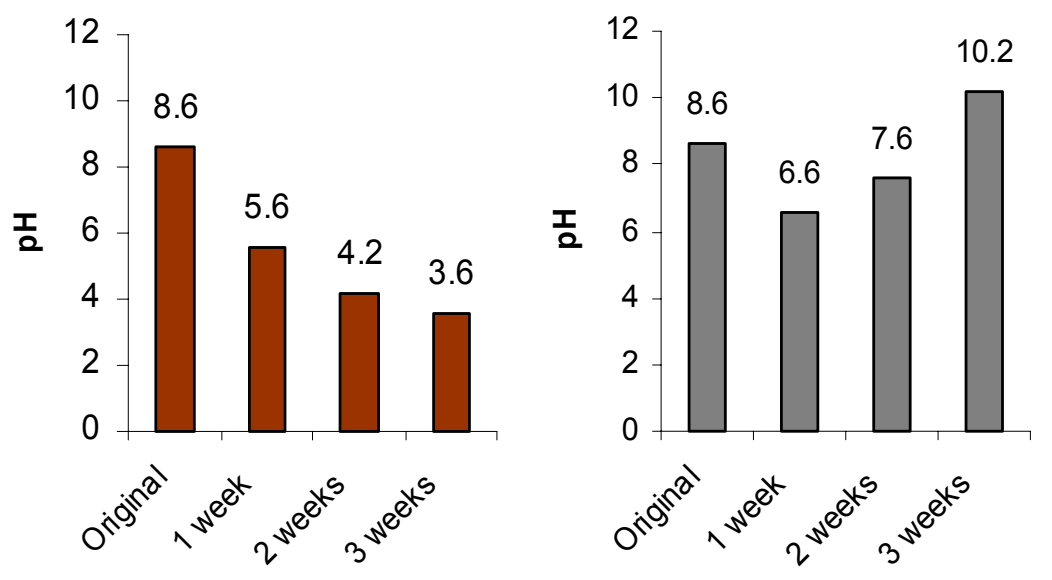

Figure 6: $\mathrm{pH}$ developments in the brick part closest to the anode, $+\mathrm{T}$ (left) and closest to the cathode, $-\mathrm{T}$ (right).

Acid $\left(\mathrm{H}^{+}\right)$and base $\left(\mathrm{OH}^{-}\right)$will be produced by the electrodes during the electrode processes and therefore reach the brick part closest to the anode $(+\mathrm{T})$ and cathode $(-\mathrm{T})$ respectively first. $\mathrm{pH}$ changes in these 2 parts was measured and illustrated in Figure 6.

In the left side of Figure 6 the $\mathrm{pH}$ development in the brick closest to the anode $(+\mathrm{T})$ is illustrated. The original $\mathrm{pH}$ value of 8.6 was reduced to 3.6 after 3 weeks. No significant $\mathrm{pH}$ reduction took place from the calculated neutralization time of 2 weeks to 3 weeks. This means that a higher carbonate amount is needed to neutralize the formatted acid than if ideal neutralization with a carbonate-clay mixture was taken place. New experiments will therefore be carried out with higher carbonate amount. The right side of Figure 6 shows the $\mathrm{pH}$ development in the brick part closest to the cathode (-T) and the figure illustrates that the expected neutralization of the produced base took place within the first 2 weeks, though between 2 and 3 weeks durations the neutralization effect ended and $\mathrm{pH}$ increased significantly. This means that the cathode claymixture behaved as under ideal conditions and that it is possible to control the $\mathrm{pH}$ developments by the cathode.

\section{Conclusion}

Preservation of murals is at present done by climate control and repainting original murals in Denmark. However, the reason for the deterioration, the salts, is not removed.

A new setup and electrode units were tested and developed in the present work for ion extraction from cultural heritage and especially church vaults. The results from the electromigration experiments showed a significant chloride extraction from the bricks and the $\mathrm{pH}$ stability of the original material was remarkably improved due to the special clay mixtures, which makes the method 
useful in connection with cultural heritage. However, improvements of the clay mixtures are still ongoing.

On the basis of successful results the fundamental possibilities for using electro kinetics for extraction of ions from masonry vaults is proven and this method might be the missing lasting method to extract the damaging salts from the vaults and thereby preserve the murals. Clarifying experiments are ongoing and the main objective is to investigate whether an unproblematic ion content can be obtained in the hole brick and to carry out laboratory experiments on a wall section with murals.

\section{Acknowledgements}

The foundation Villum Kann Rasmussen is greatly acknowledged for their financial support for this ongoing project.

\section{References}

[1] Nørregård-Nielsen, H.E., Dansk kunst - Tusind års kunsthistorie. 6.udgave,1.oplag: Gyldendal. p. 11, 2003

[2] Larsen, P.K., Desalination of painted brick vaults, Ph.d. Thesis, Department of structural engineering and materials. Technical University of Denmark. Series R, no. 52. pp.5 + $64+100-101,1999$

[3] Lubelli, B.A., Sodium chloride damage to porous building materials, Ph.d. thesis, Technische Universiteit Delft. Dissertation. pp.13-24+25-43, 2006.

[4] L. Demberger, Elektrochemische Vorgänge zur Entfeuchtung von Mauerwerk, Bautenschutz + Bausanierung, 14, pp. 115-119, 1991.

[5] Auras, M. \& Melisa, G., Kompressenentsalzung - Wirkungsprinzip, Materialien, Anwendung, Fallbeispiele, Salze im historischen Natursteinmauerwerk, IFS-Tagung 2002, Bericht Nr. 14-2002, Institut für Steinkonservierung, pp. 41-52, 2002

[6] Ottosen, L.M., Hansen, H.K., Laursen, S. \& Villumsen, A., Electrodialytic Remediation of Soil Polluted with Copper from Wood Preservation Industry, Environ. Sci. Technol., A 31, pp. 1711-1715, 1997.

[7] van Nostrand, R.V., Cook, K.L., Interpretation of Resistivity Data. Geological Survey Professional paper 499. United States Government Printing Office, Washington, 1966.

[8] Acar, Y.B., Principles of Electrokinetic Remediation, Environ. Sci. Technol, Vol. 27, No. 13, 1993.

[9] Ottosen, L.M. \& Rörig-Dalgaard, I, Drying brick masonry by electroosmosis, proceedings from the Seventh International Masonry Conference (CD-rom) London, UK, nr. 31, 2006.

[10] Larsen, P.K., Moisture physical properties of bricks: An investigation of Falkenløwe, Stralsund and Hartmann bricks, Technical report 343, Technical University of Denmark, Department of Civil Engineering, Building Materials Laboratory, 1996.

[11] Krenkler, K., Chemie des Bauwesens Band, 1 Anorganische Chemie, Springer-Verlag, pp. 96-97 + 133-136, 1980. 